\title{
Regulation of Bone Metabolism by Sex Steroids
}

\author{
Sundeep Khosla and David G. Monroe \\ Robert and Arlene Kogod Center on Aging and Endocrine Research Unit, Mayo Clinic College of Medicine, \\ Rochester, Minnesota 55905 \\ Correspondence: khosla.sundeep@mayo.edu
}

Osteoporosis is a significant public health problem, and a major cause of the disease is estrogen deficiency following menopause in women. In addition, considerable evidence now shows that estrogen is also a major regulator of bone metabolism in men. Since the original description of the effects of estrogen deficiency on bone by Fuller Albright more than 70 years ago, there has been enormous progress in understanding the mechanisms of estrogen and testosterone action on bone using human and mouse models. Although we understand more about the effects of estrogen on bone as compared with testosterone, both sex steroids do play important roles, perhaps in a somewhat compartment-specific (i.e., cancellous vs. cortical bone) manner. This review summarizes our current knowledge of sex steroid action on bone based on human and mouse studies, identifies both agreements and potential discrepancies between these studies, and suggests directions for future research in this important area.

$\mathrm{O}$ steoporosis is a significant and growing public health problem; in fact, the number of women who will experience a fracture in one year exceeds the combined number of women who will experience incident breast cancer, myocardial infarction, or stroke (Cauley et al. 2008). The major trigger for the development of osteoporosis in women is the onset of estrogen deficiency following menopause (Riggs et al. 2002). Although men also develop osteoporosis with aging, they lack the abrupt cessation of gonadal function present in women. Nonetheless, considerable evidence indicates that even in men, declining sex steroid levels with aging, particularly declining bioavailable estrogen levels, contribute to age-related bone loss (Khosla et al. 2008). Thus, a better understanding of how sex steroids regulate bone metabolism is critical not only from a biological but also a clinical perspective.

Seminal studies by Fuller Albright more than 70 years ago showed that loss of estrogen following oophorectomy or menopause led to rapid bone loss and that calcium balance could be improved in postmenopausal women with estrogen treatment (Albright 1940). Decades later, Stepan and colleagues (1989) showed that, following castration, men also experienced similar rapid bone loss; because testosterone is the major sex steroid in men, this led to the longstanding dogma that estrogen was the major regulator of bone metabolism in women, with testosterone playing the analogous role in men. Subsequent studies established that complete sex steroid deficiency in either sex was associated with an activation of bone remodel-

Editors: Gerard Karsenty and David T. Scadden

Additional Perspectives on Bone: A Regulator of Physiology available at www.perspectivesinmedicine.org

Copyright (C) 2018 Cold Spring Harbor Laboratory Press; all rights reserved; doi: 10.1101/cshperspect.a031211

Cite this article as Cold Spring Harb Perspect Med 2018;8:a031211 
ing (bone resorption and bone formation), but with a net deficit in bone formation relative to bone resorption and subsequent bone loss (Riggs et al. 2002). This review will delineate the evolution of our understanding of sex steroid regulation of bone metabolism, starting with human clinical-investigative and observational studies and then moving into data from mouse models. Although the human studies have provided important insights into physiology and the pathogenesis of osteoporosis, the mouse models have been instrumental in providing key mechanistic insights. Nonetheless, there are discrepancies between the human and mouse studies, and these will be highlighted where appropriate, with suggestions for potential resolutions to disparate findings. Although there is correlative evidence for relationships between weak adrenal androgens (Khosla et al. 1998) or progesterone (Prior 1990) and bone mineral density (BMD), direct evidence from interventional studies in humans is inconsistent for these steroids, so the focus will be on estrogen and testosterone effects on bone.

\section{HUMAN STUDIES}

\section{Evidence from Estrogen Receptor- or Aromatase-Deficient Males}

The traditional notion that estrogen was the dominant sex steroid regulating bone metabolism in women, whereas testosterone played the analogous role in men was challenged by the description in 1994 of the skeletal phenotype of a 28-year-old male with homozygous mutations in the estrogen receptor (ER) $\alpha$ gene, resulting in a nonfunctional ER (Smith et al. 1994). Despite normal testosterone and elevated estrogen levels, this individual had unfused epiphyses and osteopenia, with a spine BMD that was more than two standard deviations (SDs) below the mean for 15-year-old boys (the patient's bone age). Subsequent to this report, two males with complete deficiency of the enzyme responsible for the final step in the synthesis of estrogens, aromatase, were described (Carani et al. 1997; Bilezikian et al. 1998) with a virtually identical skeletal phenotype to the
$\mathrm{ER} \alpha$-deficient male. These "experiments of nature" clearly showed that, even in boys, estrogen was essential for epiphyseal closure and for the acquisition of bone mass during puberty in males. A subsequent description of a transiliac crest bone biopsy of the ER $\alpha$-deficient male showed reduced cancellous bone volume and cortical width (Smith et al. 2008). Interestingly, in contrast to estrogen-deficient women or hypogonadal men who typically have increased bone remodeling (Riggs et al. 2002), the ER $\alpha$ deficient male had markedly reduced indices of bone resorption and formation. This suggests the possibility that loss of the ligand (estrogen) may lead to reduced bone mass through a different mechanism than loss of the receptor. Indeed, this possibility is supported by numerous ligand-independent effects of ER $\alpha$ in bone and other tissues (Ciana et al. 2003). However, cultured bone marrow stromal cells from the $\mathrm{ER} \alpha$-deficient male also showed increased ER $\beta$ levels by Western analysis (Smith et al. 2008). The role of ER $\beta$ in bone metabolism is discussed later in greater detail in the mouse models, but at least in this human case report the high circulating estrogen and increased bone ER $\beta$ levels could not compensate for loss of $\mathrm{ER} \alpha$ to preserve bone mass. Whether the low bone turnover with loss of $\mathrm{ER} \alpha$ was because of the absence of ligand-independent effects of $\mathrm{ER} \alpha$ or some degree of compensatory suppression of bone turnover because of the activation of ER $\beta$ by the elevated circulating estrogen levels remains unclear and warrants further mechanistic studies using mouse models.

\section{Observational Studies}

Extensive studies in women through the menopausal transition have confirmed Fuller Albright's original observations regarding the key role of estrogen in regulating bone metabolism in women. Specifically, as shown in Figure 1, the decline in serum estradiol levels (and accompanying increase in serum follicle stimulating hormone [FSH] levels) through menopause is closely associated with an increase in osteoclastic bone resorption (urine N-telopeptide of type I collagen [NTx]) (Sowers et 


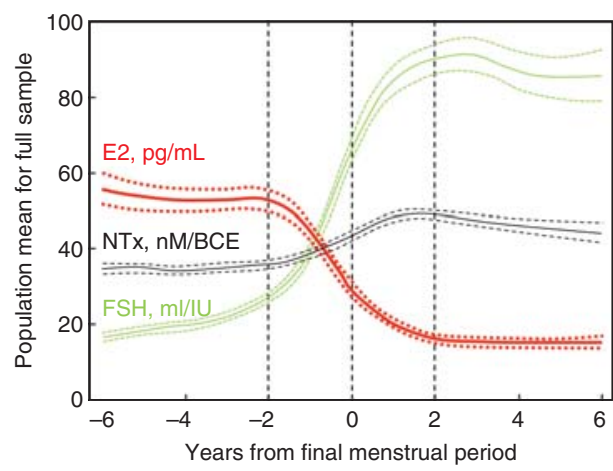

Figure 1. Changes in estradiol, follicle-stimulating hormone (FSH), and bone resorption through the menopausal transition. Population mean bone resorption marker (urine N-telopeptide of type I collagen $[\mathrm{NTx}]$ ), serum estradiol, and serum FSH levels in relation to years from final menstrual period. Dashed lines denote the $95 \%$ confidence intervals. (From Sowers et al. 2013; reproduced, with permission, from Oxford University Press (C) 2013.)

al. 2013). Conversely, because the postmenopausal ovary continues to produce androgens, serum testosterone or other androgen levels do not change significantly across menopause (Handelsman et al. 2016), arguing against a role for androgens in contributing to postmenopausal bone loss. Moreover, the specific role, if any, of the relatively low circulating androgen levels in women in regulating bone metabolism has been difficult to identify in human studies and will be considered further in the mouse models discussed later.

Numerous observational studies in men have documented that, consistent with the findings from the $\mathrm{ER} \alpha$ - and aromatase-deficient males, serum estrogen levels were more closely correlated with BMD and bone turnover markers than were serum testosterone levels. Using a population-based age-stratified sample of 346 men aged 23-90 years (Khosla et al. 1998), we found that serum total testosterone and estrogen (estradiol + estrone) levels decreased over the life span by $30 \%$ and $12 \%$, respectively, but the bioavailable (or non-sex-hormone-binding globulin-bound) testosterone and estrogen levels decreased by $64 \%$ and $47 \%$, respectively. Using multivariate analyses, serum bioavailable estrogen level was the consistent independent predictor of BMD in men. Thus, serum bioavailable estrogen levels not only declined significantly with age in men, but also correlated with declining BMD levels, suggesting that estrogen deficiency with aging may contribute to bone loss not only in women, but also in men. Since these original findings, numerous subsequent analyses have confirmed the closer association of BMD and rates of bone loss with serum bioavailable estrogen as compared with testosterone levels in men (for review, see Khosla et al. 2008).

\section{Interventional Studies}

The evidence from interventional studies is overwhelming that estrogen is the dominant sex steroid regulating bone metabolism in women. The most rigorous demonstration of this comes from the results of the Women's Health Initiative, which randomized 16,608 postmenopausal women aged 50 to 79 years to receive conjugated equine estrogen $(0.625 \mathrm{mg} / \mathrm{d})$ and medroxyprogestorone acetate (to prevent endometrial hyperplasia, $2.5 \mathrm{mg} / \mathrm{d}$ ) or placebo for an average of 5.6 years (Cauley et al. 2003). Estrogen treatment increased BMD at multiple skeletal sites as compared with placebo and also reduced hip fracture risk by $33 \%$. In contrast to estrogen, evidence that the low circulating testosterone levels present in women have a significant impact on bone metabolism is weak or inconsistent (Raisz et al. 1996).

To directly compare estrogen versus testosterone effects on bone metabolism in men, we performed an interventional study in which endogenous estrogen and testosterone production were pharmacologically suppressed and physiological levels of each were maintained by exogenous replacement using estrogen and testosterone patches (Falahati-Nini et al. 2000). Following baseline measurements of bone resorption (urinary deoxypyridinoline [Dpd] and NTx) and bone formation (serum osteocalcin and amino-terminal propeptide of type I collagen [PINP]) markers, the men were randomized into four groups: group $\mathrm{A}(-\mathrm{T},-\mathrm{E})$ discontinued both patches; group $\mathrm{B}(-\mathrm{T},+\mathrm{E})$ discontinued the testosterone but remained on 


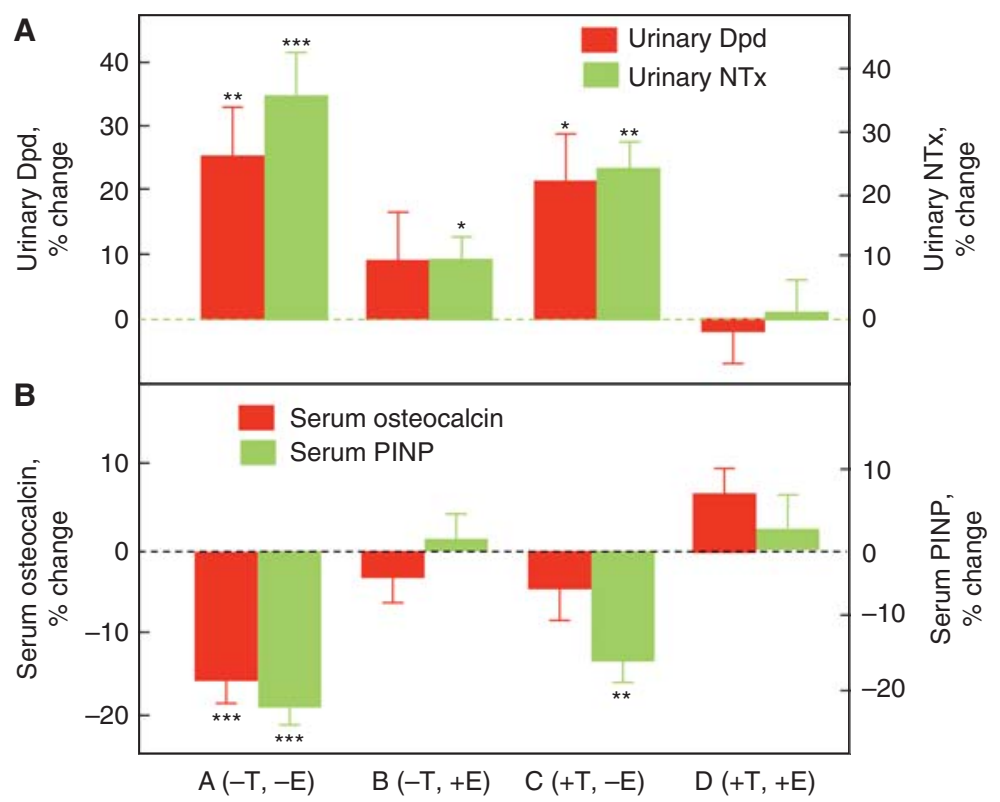

Figure 2. Deconvoluting the effects of estrogen versus testosterone on bone metabolism in men. Percent changes in (A) bone-resorption markers (urinary deoxypyridinoline [Dpd] and N-telopeptide of type I collagen [NTx]), and (B) bone-formation markers (serum osteocalcin and amino-terminal extension peptide of type I collagen [PINP]) in a group of elderly men (mean age $68 \mathrm{yr}$ ) made acutely hypogonadal and treated with an aromatase inhibitor (group A), treated with estrogen alone (group B), testosterone alone (group C), or both (group D). See text for details. Asterisks indicate significance for change from baseline: ${ }^{*} P<0.05 ;{ }^{* *} P<0.01 ;{ }^{* *} P<0.001$. (From Falahati-Nini et al. 2000; adapted, with permission, from the American Society for Clinical Investigation (C) 2000.)

the estrogen patch; group C $(+\mathrm{T},-\mathrm{E})$ discontinued the estrogen but remained on the testosterone patch; and group $\mathrm{D}(+\mathrm{T},+\mathrm{E})$ continued both patches. As shown in Figure 2A, significant increases in the bone resorption markers (Dpd and NTx) in the group with complete sex steroid withdrawal (group A) were entirely prevented by replacement of both sex steroids (group D) and almost completely prevented by estrogen replacement alone (group B). In contrast, testosterone replacement in the absence of conversion to estrogen (because all men were also maintained on an aromatase inhibitor) was largely ineffective. A formal statistical analysis using a two-factor analysis of variance (ANOVA) model established a highly significant effect of estrogen, but not testosterone, on bone resorption, and we estimated based on these data that, in men, estrogen accounted for $>70 \%$ of the total effect of sex steroids on bone resorption, whereas testosterone could account for no more than $30 \%$ of the effect. Acute sex steroid deficiency clearly reduced the bone-formation markers (Fig. 2B), but the effects of selective replacement differed for osteocalcin versus PINP. Reductions in osteocalcin were prevented either by estrogen or testosterone replacement, whereas only estrogen, but not testosterone, was able to prevent the reduction in PINP levels. Because osteocalcin is stored in the bone matrix, serum osteocalcin levels may reflect not only bone formation but also bone resorption (Ivaska et al. 2004). In contrast, PINP is a pure bone-formation marker, so this evidence indicates that estrogen was the major regulator of bone formation in men. Note that these acute (3-week) effects of sex steroid deficiency are, in fact, different from the chronic effects of sex steroid deficiency on bone-formation markers. In the latter situation, the "coupling" of bone resorption to bone formation (Khosla 2012) leads to increased bone 
formation, but with a net gap between resorption and formation and ongoing bone loss (Riggs et al. 2002).

The findings from this study were largely confirmed more recently by Finkelstein and colleagues (Finkelstein et al. 2016) who used a somewhat different study design involving pharmacological induction of hypogonadism in men followed by graded doses of testosterone replacement with or without an aromatase inhibitor. Similar to our earlier study, changes in bone resorption and formation markers were predominantly regulated by estrogen. Moreover, testosterone, in the absence of aromatization to estrogen, was unable to prevent decreases in BMD at multiple sites. Collectively, these two and additional interventional studies (reviewed in Khosla 2015) using variations of the approaches used in the studies described above now provide compelling evidence in humans that, in both women and men, estrogen is the dominant sex steroid regulating bone metabolism. However, testosterone likely does play an important role during growth and, directly or indirectly (via the growth hormone/insulinlike growth factor [IGF] system) (Almeida et al. 2017), contributes to the periosteal apposition that results in larger bones in men as compared with women. We will revisit the findings from this human study in light of more recent findings in mice using cell-specific deletion of the androgen receptor (AR), which may require a reinterpretation of the human data.

\section{Potential Mediators of Estrogen Action on Bone in Humans}

A limited number of interventional studies have addressed potential mechanisms or mediators of estrogen action on bone in vivo in humans. For example, based mainly on studies in ovariectomized rodents, a number of proinflammatory cytokines have been suggested as mediators of the effects of estrogen on bone resorption, with tumor necrosis factor (TNF)- $\alpha$ and interleukin (IL)-1 $\beta$ being perhaps the most consistent estrogen-regulated cytokines in the rodent models (for review, see Weitzmann and Pacifici 2006). To address this issue in humans, we designed a study using estrogen withdrawal followed by blockade of either TNF- $\alpha$ or IL-1 $\beta$ action in postmenopausal women (Charatcharoenwitthaya et al. 2007). Specifically, postmenopausal women were treated with estrogen for 60 days followed by discontinuation of the estrogen for 3 weeks in the setting of either saline injections (control), treatment with a TNF- $\alpha$ blocker (etanercept), or an IL- $1 \beta$ blocker (anakinra). Because of the risk of infection, both blockers could not be used together in humans. As shown in Figure 3, the increase in bone resorption in the control women was significantly blocked (by $\sim 50 \%$ ) by the TNF- $\alpha$ blocker and to a lesser extent by the IL-1 $\beta$ blocker, showing that in humans TNF- $\alpha$ and perhaps IL-1 $\beta$ mediate the antiresorptive effects of estrogen on bone. In this model, neither

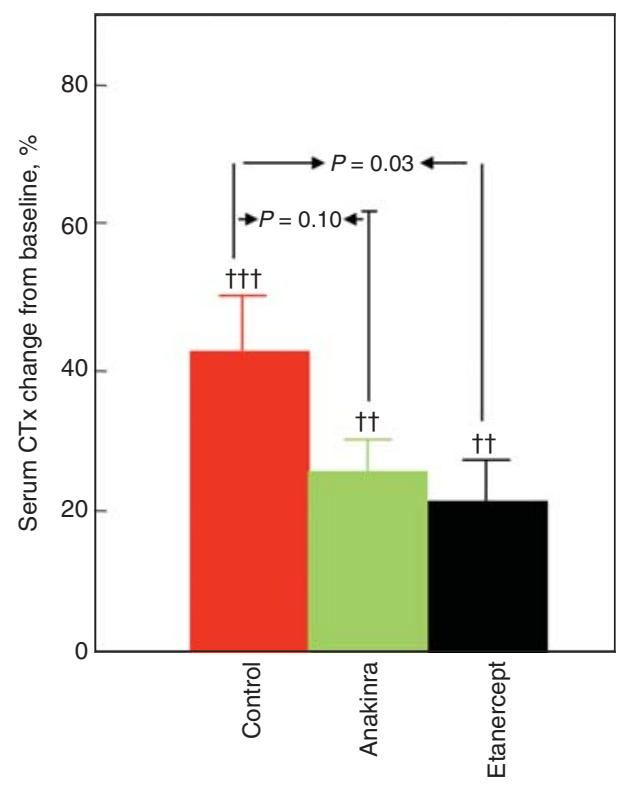

Figure 3. Effects of interleukin (IL)-1 or tumor necrosis factor (TNF) blockade on bone resorption in women following estrogen withdrawal. Proportional change (\%) in serum C-telopeptide of type I collagen (CTx) in postmenopausal women treated for 60 days with transdermal estradiol, made acutely estrogen deficient, and treated with saline (control), an IL-1 blocker (anakinra), or a TNF blocker (etanercept). (From Charatcharoenwitthaya et al. 2007; reproduced, with permission, from John Wiley and Sons (C) 2007.) 
blocker was able to prevent the decrease in bone formation following estrogen withdrawal, indicating that the maintenance of bone formation by estrogen was likely independent of these cytokines.

Another key factor regulating osteoclast development is receptor activator of nuclear factor $\kappa \mathrm{B}$ (RANK) ligand (RANKL) produced by a number of cells in the bone microenvironment, including osteocytes and osteoblast lineage cells (for review, see Kearns et al. 2008). Indeed, RANKL is both necessary and sufficient for osteoclast differentiation given permissive concentrations of macrophage colony-stimulating factor (M-CSF), and it also enhances the activity and prolongs the life span of osteoclasts by decreasing apoptosis. To address the issue of estrogen regulation of RANKL, we isolated bone marrow mononuclear cells expressing RANKL on their surfaces using flow cytometry and the decoy RANKL receptor, osteoprotegerin (OPG), as a probe (OPG-Fc-FITC) (Eghbali-Fatourechi et al. 2003). The marrow cells were characterized as osteoblast lineage, T cells, or $\mathrm{B}$ cells by using antibodies against bone alkaline phosphatase, CD3, and CD20, respectively, in premenopausal women, untreated postmenopausal women, or estrogen-treated postmenopausal women. We found that the fluorescence intensity of OPG-Fc-FITC, an index of the surface concentration of RANKL per cell, was increased in the estrogen-deficient postmenopausal women as compared with the premenopausal women by two- to threefold for each of the cell populations, and these increases were reversed by estrogen treatment (Fig. 4). These data show that, directly or indirectly, estrogen deficiency increases RANKL production by a number of cell populations in the bone microenvironment, contributing to the increase in bone resorption. Notably, the increased bone resorption in postmenopausal women can now be entirely reversed clinically by treatment with denosumab, a human monoclonal antibody to RANKL (Cummings et al. 2009).

There is also considerable evidence from human studies that estrogen regulates the production of the proposed inhibitor of Wnt signaling, sclerostin (Drake and Khosla 2017). A number of studies have shown that treatment of postmenopausal women with estrogen (Modder et al. 2011a,b; Fujita et al. 2014; Farr et al. 2015) or with the selective ER modulator, raloxifene (Chung et al. 2012), reduces circulating sclerostin levels using several different assays for sclerostin. Because there is some question as to whether serum sclerostin levels reflect changes in the bone microenvironment, we

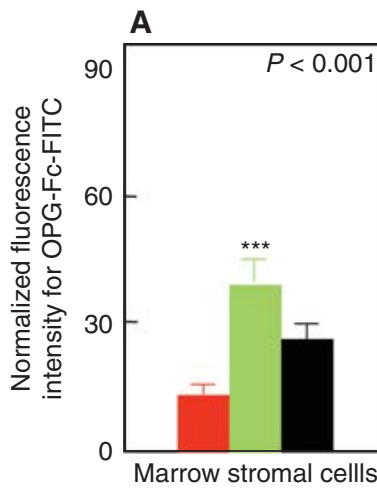

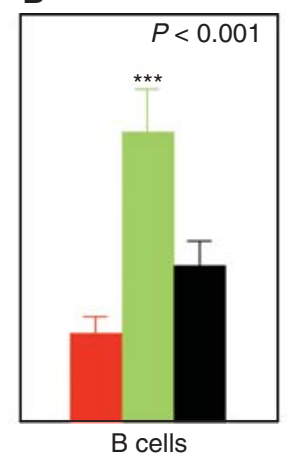

C

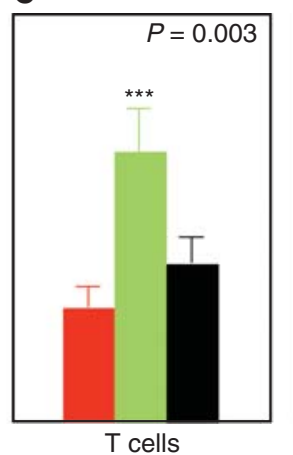

D

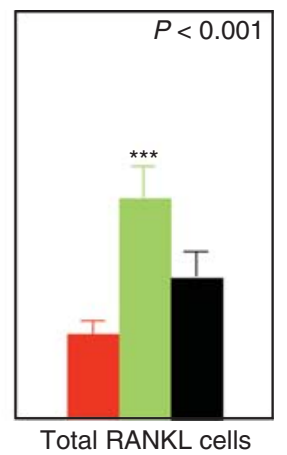

Figure 4. Effects of estrogen on cell surface receptor activator of nuclear factor $\kappa \mathrm{B}$ ligand (RANKL) expression in postmenopausal women. Changes in osteoprotegerin (OPG)-Fc-FITC fluorescence as an index of mean RANKL surface concentration per cell are shown for premenopausal women (red bars), estrogen-deficient postmenopausal women (green bars), and estrogen-treated postmenopausal women (black bars). $(A-D)$ The various cell populations as indicated. $P$-values by analysis of variance (ANOVA) are as indicated. ${ }^{* * *} P<0.001$ versus the premenopausal women. (From Eghbali-Fatourechi et al. 2003; reproduced, with permission, from the American Society for Clinical Investigation (C) 2003.) 
recently examined bone sclerostin messenger RNA (mRNA) levels in needle bone biopsies from either untreated or estrogen-treated postmenopausal women (Farr et al. 2015). Consistent with decreases in serum sclerostin levels using two different assays, bone sclerostin mRNA levels were also $41 \%$ and $48 \%$ lower when assessed by RNAseq and QPCR, respectively, in the estrogen-treated versus control women. Estrogen treatment also reduced bone mRNA levels of the sclerostin-related protein, sclerostin-containing protein 1 (SOSTDC1), which is also an inhibitor of Wnt- and BMPsignaling (Fujita et al. 2014). Given increasing evidence that sclerostin modulates not only bone formation, but also bone resorption ( Tu et al. 2015), these findings suggest that sclerostin may be in the pathway of estrogen action on bone, as shown further by the mouse models discussed later. Moreover, similar to the translation of RANKL inhibition to a new therapeutic, sclerostin inhibition using a humanized monoclonal antibody, romosozumab (Cosman et al. 2016), results in a profound increase in bone formation and reduction in bone resorption in postmenopausal women, qualitatively similar to the pattern of changes in bone turnover induced by estrogen treatment (Drake and Khosla 2017).

\section{MOUSE MODELS}

\section{Deletion of ER or AR in Bone Cells}

The effects of estrogen on bone are mediated by two related, but distinct, receptors, ER $\alpha$ and ER $\beta$ (Almeida et al. 2017). Although the role of $\mathrm{ER} \alpha$ in regulating bone metabolism in mice has been much more extensively studied than that of ER $\beta$, our understanding even of ER $\alpha$ action on bone is still far from complete. Sims and colleagues (2002) initially studied mice with global deletion of ER $\alpha$ that had high circulating estrogen levels in females and increased testosterone levels in females and males. Deletion of $E R \alpha$ in either sex led to a decrease in bone turnover and increase in cancellous bone mass, but a decrease in cortical thickness. This indicated that, in cancellous bone, activation of
ER $\beta$ by the high estrogen levels or the AR by the high testosterone levels in females was able to compensate for loss of ER $\alpha$ in cancellous but not cortical bone. Similarly, the high testosterone levels in males were able to compensate for loss of ER $\alpha$ in cancellous but not cortical bone. Deletion of ER $\beta$ did not alter sex steroid levels in either sex, had no effect on bone in males, and led to a decrease in bone resorption and increase in cancellous bone volume but not in cortical thickness in females at 10 weeks of age. In contrast, a subsequent study by Windahl and colleagues (1999) did find an increase in periosteal and endosteal circumference in female ER $\beta$ knockout mice. Thus, although the global ER-deletion models were confounded by altered sex steroid levels in the ER $\alpha$ knockout mice, they did show that (1) loss of ER $\alpha$ compromised cortical bone thickness in both sexes, and (2) ER $\beta$ did not regulate bone metabolism in males but could either compensate for loss of $\mathrm{ER} \alpha$ in females, at least in the setting of elevated estrogen levels, or when $\mathrm{ER} \alpha$ was present, $\mathrm{ER} \beta$ appeared to antagonize $\mathrm{ER} \alpha$ action on bone.

Similar to the global ER $\alpha$ knockout mice, male mice with global deletion of AR were found to have significant alterations in circulating sex steroid levels, specifically, reduced serum testosterone levels (Yeh et al. 2002; Kawano et al. 2003). Thus, although male AR knockout mice had reduced cancellous and cortical bone volume because of increased bone resorption, it is unclear whether this was the result of loss of the AR in bone cells or the concomitant hypogonadism. In contrast to male AR knockout mice, female AR knockout mice did not have any skeletal deficits.

Although these global ER and AR knockout mice provided some insights, more conclusive data on the roles of these receptors in bone metabolism has come from studies using Cre/ LoxP technology for cell-specific deletions. Although the original description by Oursler and colleagues of the presence of ERs in avian (Oursler et al. 1991) and human (Oursler et al. 1994) osteoclasts and effects of estrogen on directly inhibiting osteoclast activity had been met with some skepticism, recent cell-specific $\mathrm{ER} \alpha$ deletions, in fact, point to the osteoclast as 
a key target of estrogen action in females, but not males. Thus, ER $\alpha$ deletion either relatively early in the myeloid lineage using the LysM-Cre (Martin-Millan et al. 2010) or in the more differentiated osteoclast lineage using the Ctsk-Cre (Nakamura et al. 2007) led to reductions in cancellous bone mass because of increased osteoclast numbers and high levels of bone resorption, but only in female mice. In contrast, AR deletion in myeloid cells using the LysM-Cre did not alter cancellous or cortical bone in either sex (Ucer et al. 2015). Thus, ER $\alpha$ is critical for directly regulating osteoclast number and bone resorption in female but not male mice, and the AR does not appear to directly regulate osteoclasts in either sex.

A number of studies have used osteoblast lineage Cre models to delete sex steroid receptors at various stages of osteoblast differentiation. Deletion of ER $\alpha$ in mesenchymal progenitors (using Prxl-Cre) or in osteoprogenitors (using Osx-Cre) impaired Wnt/ $\beta$-catenin signaling, reducing proliferation and differentiation of periosteal cells (Almeida et al. 2013). This signaling pathway was important for optimal cortical bone accrual in females with a transient effect in males, but did not require the presence of estrogen (i.e., was a ligand-independent effect of $E R \alpha$ ). In contrast to cortical bone, deletion of ER $\alpha$ using either the Prx1-Cre or Osx-Cre had minimal or no effect in cancellous bone in either sex (Almeida et al. 2013).

$\mathrm{ER} \alpha$ has also been deleted later in osteoblast differentiation using the Colla1-Cre (Almeida et al. 2013) but perhaps, surprisingly, neither female nor male mice with $\mathrm{ER} \alpha$ deletion using this Cre model showed deficits in bone mass or microarchitecture at $4,8,12$, or 26 weeks of age. Interestingly, the $E R \alpha^{f / f}$;Colla1-cre mice did show an increase in osteoblast apoptosis in cancellous bone, but this did not translate into structural alterations in bone. In contrast to these findings using the Colla1-Cre, studies using Cre models activated even later in osteoblast differentiation (i.e., in the late osteoblast/ osteocyte) have generally found a reduction in bone mass in both sexes associated with low bone-formation rates, although the data are somewhat inconsistent. Thus, two studies used the osteocalcin (Ocn)-Cre and found deficits in cancellous and in cortical bone associated with reduced cancellous bone formation rates in female mice (Maatta et al. 2013; Melville et al.2014). Although these deficits were present in female mice at 3-4 months of age, they appeared to take longer to develop in male mice and only became evident at 6 months of age.

Studies using the Dmp1-Cre, which overlaps with the Ocn-Cre but is expressed perhaps somewhat later in osteoblast differentiation, have yielded somewhat conflicting results. Thus, Windahl et al. (2013) reported that male but not female mice with $\mathrm{ER} \alpha$ deletion using the Dmp1-Cre had reduced cancellous bone mass associated with decreased bone formation. In contrast, Kondoh et al. (2014) found the opposite-reduced cancellous bone mass and decreased bone formation in female but not male mice. Cortical bone was unaffected in either sex in both studies. The reasons for these discrepant findings are unclear, but the collective findings using the Ocn- and Dmp1Cre models do indicate that $\mathrm{ER} \alpha$ signaling is likely important in mature osteoblasts/osteocytes and that $\mathrm{ER} \alpha$ regulates bone formation, at least in part through regulating osteoblast apoptosis.

Cell-specific deletion of ER $\beta$ either in osteoprogenitor cells (Prx1-Cre) or in more mature osteoblasts (Colla1-Cre) has been shown to have the opposite effect to ER $\alpha$ deletion, namely, an increase in cancellous bone mass but without an alteration in cortical bone mass in female mice (Nicks et al. 2016). This compartment-specific effect of ER $\beta$ deletion (i.e., an increase in cancellous but not cortical bone mass) is of interest, as previous studies in human (Bord et al. 2001) and mouse (Modder et al. 2004) bone have found that both $\mathrm{ER} \alpha$ and ER $\beta$ are expressed in cancellous bone, whereas cortical bone mainly contains $\mathrm{ER} \alpha$. In addition, ex vivo studies found an increase in the ratio of colony-forming unit osteoblasts (CFU-OBs) to CFU fibroblasts (CFU-Fs) in the ER $\beta$-deleted mice, indicating increased differentiation of osteoblast precursor cells into osteoblasts in the absence of ER $\beta$. Consistent with findings in reproductive tissues (Hall and McDonnell 
1999), ER $\beta$ was shown to antagonize $\mathrm{ER} \alpha$ action in osteoblastic cells (Nicks et al. 2016). Thus, ER $\beta$ likely plays an antagonistic role to $\mathrm{ER} \alpha$ in bone, and this effect is predominant in cancellous bone. This point will be considered further below in attempting to understand the compartment-specific effects of sex steroids in females and males.

In contrast to the absence of skeletal effects of AR deletion in myeloid/osteoclast lineage cells, deletion of the AR in osteoprogenitor cells (Prx1-Cre) resulted in osteopenia and increased bone resorption in cancellous, but not in cortical, bone in male mice, with female mice having a much milder but qualitatively similar phenotype (Ucer et al. 2015). Very similar findings were reported using the Colla1-, Ocn-, and Dmp1-Cre mice crossed with floxed AR mice (Notini et al. 2007; Chiang et al. 2009; Sinnesael et al. 2012), establishing the consistency of this observation across osteoblast lineage Cre models. Moreover, these unequivocal effects of AR signaling in cancellous bone in male mice appear to be at odds with the clear evidence from human studies noted earlier that estrogen is the dominant regulator of bone metabolism in men. This apparent discrepancy between the mouse and human data will be considered below.

Table 1 attempts to summarize the now extensive body of work from multiple laboratories regarding global, osteoblast-, or osteoclast-lineage deletion of $\mathrm{ER} \alpha, \mathrm{ER} \beta$, or AR. Keeping in mind that not all of the data are consistent across laboratories, the table presents the overall picture that is emerging. Thus, although global $\mathrm{ER} \alpha$ deletion is confounded by profound alterations in circulating sex steroid levels, both female and male ER $\alpha$ knockout mice do have reductions in cortical bone mass. The most unequivocal findings are the following: (1) ER $\alpha$ deletion in osteoclasts leads to reduced cancellous (but not cortical) bone mass in females, but not males; (2) AR deletion in osteoblast lineage cells leads to reduced cancellous (but not cortical) bone mass in males, with a milder phenotype in females; and (3) ER $\beta$ deletion in osteoblast lineage cells leads to increased cancellous (but not cortical) bone mass in females. ER $\alpha$ deletion in osteoblast lineage cells has generally resulted in reductions in cancellous and perhaps cortical bone mass in females and cancellous bone mass in males, but these findings have been somewhat variable across laboratories. However, an important caveat to all of these studies is that the receptor deletion, although cell-specific, has been present since conception. As such, the skeletal findings reflect largely developmental effects of these receptors rather than their role in the adult skeleton. Further studies using both cell- and temporalspecific deletion of these receptors using inducible models are needed to address this limitation and further clarify the role of sex steroid receptors on the adult murine skeleton. In addition, for each of these receptor deletions, the severity of the published phenotypes depends on the

Table 1. Summary of effects of deletion of sex steroid receptors, either globally or in specific cells, on bone mass

\begin{tabular}{|c|c|c|c|c|c|c|c|}
\hline \multirow{2}{*}{\multicolumn{2}{|c|}{ Receptor deleted }} & \multicolumn{2}{|c|}{ Global } & \multicolumn{2}{|c|}{$\begin{array}{c}\text { Osteoblast lineage/ } \\
\text { osteocyte }\end{array}$} & \multicolumn{2}{|c|}{ Myeloid/osteoclast } \\
\hline & & Cancellous & Cortical & Cancellous & Cortical & Cancellous & Cortical \\
\hline \multirow[t]{3}{*}{ Female } & $\mathrm{ER} \alpha$ & $\uparrow$ & $\downarrow$ & $(\downarrow)$ & $(\downarrow)$ & $\downarrow$ & $\leftrightarrow$ \\
\hline & $\mathrm{ER} \beta$ & $\uparrow$ & $\leftrightarrow$ & $\uparrow$ & $\leftrightarrow$ & NT & NT \\
\hline & $\mathrm{AR}$ & $\leftrightarrow$ & $\leftrightarrow$ & $\downarrow$ & $\leftrightarrow$ & $\leftrightarrow$ & $\leftrightarrow$ \\
\hline \multirow[t]{3}{*}{ Male } & $\mathrm{ER} \alpha$ & $\uparrow$ & $\downarrow$ & $(\downarrow)$ & $\leftrightarrow$ & $\leftrightarrow$ & $\leftrightarrow$ \\
\hline & $\mathrm{ER} \beta$ & $\leftrightarrow$ & $\leftrightarrow$ & NT & NT & NT & NT \\
\hline & $\mathrm{AR}$ & $\downarrow$ & $\downarrow$ & $\downarrow$ & $\leftrightarrow$ & $\leftrightarrow$ & $\leftrightarrow$ \\
\hline
\end{tabular}

Parentheses surrounding arrows indicate somewhat conflicting data, with the overall evidence pointing to the direction noted.

NT, Not tested. 
efficiency of deletion of the gene as well as the specificity of the deletion in the particular cell type, which is not always clearly assessed in the original papers.

\section{$\mathrm{ER} \alpha$ Deletion in the Central Nervous System}

As shown by the above studies, ER $\alpha$ clearly has direct effects on bone, acting to preserve or enhance bone mass. In contrast, several studies indicate that this positive peripheral effect of $\mathrm{ER} \alpha$ may be counterbalanced by a negative central effect. Thus, deletion of ER $\alpha$ in the central nervous system (CNS) using the nestin-Cre resulted in an increase in cancellous and cortical bone mass in female mice associated with increased bone formation (Ohlsson et al. 2012). The CNS ER $\alpha$ knockout mice had normal sex steroid, serotonin, and catecholamine levels, but did have increased serum leptin levels. Generally similar findings were noted in a subsequent study using POMC-Cre mice, in which the $\mathrm{ER} \alpha$ deletion was more specific for hypothalamic neurons (Farman et al. 2016). Although this negative central effect of estrogen signaling on bone is of interest, the net effect of estrogen deficiency in mice and humans is bone loss, arguing that the peripheral effects of $\mathrm{ER} \alpha$ signaling dominate over these negative central effects.

\section{Role of T and B Cells}

A series of studies, principally in mice, have provided substantial evidence for an important role of $\mathrm{T}$ cells in mediating ovariectomy-induced bone loss. The fundamental observation is that ovariectomy leads to an increase in TNFproducing $\mathrm{T}$ cells, which in turn results in an increase in RANKL-induced osteoclast formation (for review, see Pacifici 2012). A number of mechanisms have been proposed for the expansion of TNF-producing $\mathrm{T}$ cells, including increased antigen presentation, stimulation of IL-7 and interferon (IFN)- $\gamma$ production, and down-regulation of transforming growth factor (TGF)- $\beta$ production (Pacifici 2012). Activated $\mathrm{T}$ cells also increase RANKL and M-CSF production by bone marrow stromal cells through
CD40L and DLK1/FA-1 (Pacifici 2012). A further intriguing aspect of this work has been the recent evidence linking sex steroid deficiency in mice to gut microbiota ( $\mathrm{Li}$ et al. 2016). Specifically, sex steroid deficiency appears to lead to increased gut permeability, an expansion of Th17-activated T cells, and subsequent up-regulation of osteoclastogenic cytokines, including TNF- $\alpha$, RANKL, and IL-17. Remarkably, germ-free mice lacking an intestinal microbiome are resistant to sex steroid deficiency-induced cancellous bone loss. This area is not without some controversy, however, as various mouse strains lacking $\mathrm{T}$ cells do lose cancellous bone following ovariectomy (Lee et al. 2006). In addition, mice lacking RANKL specifically in T cells lose bone similar to control mice following ovariectomy (Nakashima et al. 2011; Onal et al. 2012).

There is also evidence linking B cells to ovariectomy-induced bone loss in mice. Specifically, deletion of RANKL from B cells prevents cancellous bone loss and increased bone resorption following ovariectomy in mice (Onal et al. 2012). Ovariectomy increases the number of B cells (Masuzawa et al. 1994), although, in humans, estrogen deficiency may also increase RANKL expression per cell on B cells (EghbaliFatourechi et al. 2003). However, the precise mechanisms by which estrogens or androgens control B-cell numbers remain unclear at this point.

\section{Potential Mediators of Estrogen Action from Mouse Models Relative to Findings in Humans}

As noted earlier, there is relative consistency between the mouse data showing an important role for TNF- $\alpha$ in mediating ovariectomyinduced bone loss in mice (Weitzmann and Pacifici 2006) and human studies using the TNF- $\alpha$ blocker (etanercept) (Charatcharoenwitthaya et al. 2007). Estrogen deficiency also leads (directly or indirectly) to increased RANKL production by a number of cells, or an expansion of cells expressing RANKL, in the bone microenvironment in mouse models (Pacifici 2012), again generally consistent with 
human studies showing increased RANKL expression on bone marrow stromal cells, T cells, and $\mathrm{B}$ cells in estrogen deficient as compared with estrogen-sufficient women (Eghbali-Fatourechi et al. 2003). The human studies showing regulation of circulating sclerostin and bone SOST mRNA levels by estrogen (Modder et al. 2011a,b; Fujita et al. 2014; Farr et al. 2015) are also consistent with studies in mice with Lrp5 mutations rendering them resistant to sclerostin (Niziolek et al. 2015). These mice have absent or markedly attenuated bone loss following ovariectomy, indicating a potential role for sclerostin in mediating estrogen-deficiency bone loss. The suppression of SOSTDC1 mRNA levels in bone in postmenopausal women treated with estrogen (Fujita et al. 2014) is also consistent with the observation that mice with osteocyte-specific deletion of $\mathrm{ER} \alpha$ have increased bone sostdc1 mRNA levels (Kondoh et al. 2014), although a causative role for sostdcl in facilitating or mediating estrogen deficiency-induced bone loss remains to be established. ER $\alpha$ deletion in mesenchymal/stromal cells has also been shown to increase the expression of SDF1 and MMP13 (Ucer et al. 2016), which may play a role in mediating increased endocortical bone resorption following estrogen deficiency. However, these findings have not yet been validated in human studies.

\section{DISCREPANCIES BETWEEN THE HUMAN AND MOUSE STUDIES AND POSSIBLE RESOLUTIONS}

Although there generally are consistencies between the human and mouse data regarding sex steroid action on bone, and the mouse studies have been instrumental in defining the specific roles of $\mathrm{ER} \alpha, \mathrm{ER} \beta$, and $\mathrm{AR}$ in bone metabolism, there is a fundamental discrepancy between the human and mouse models that needs to be resolved. As noted earlier, the collective evidence from both the observational and interventional human studies is overwhelming that estrogen plays a much more significant role in regulating bone metabolism in men than testosterone (for review, see Khosla et al. 2008). In contrast, four separate studies in mice, discussed above, have found that AR deletion in osteoblast lineage cells in male mice leads to reduced cancellous bone volume and cancellous number associated with increased osteoclast numbers (Notini et al. 2007; Chiang et al. 2009; Sinnesael et al. 2012; Ucer et al. 2015). Moreover, neither AR nor ER $\alpha$ deletion has any effect on cortical bone in male mice.

One possibility is that mice may be fundamentally different from humans, at least in terms of sex steroid regulation of male bone. This may be a result of the fact that aromatase expression in rodents is predominantly in the brain and gonads, whereas humans have extensive aromatase expression across tissues (Simpson et al. 1997). On the other hand, it may be that the original interpretation of the human data (including by our group) was incomplete, particularly in light of the subsequent findings in mice. Thus, in our original human study using depletion of sex steroids and selective replacement with estrogen or testosterone (Falahati-Nini et al. 2000), we did observe a small increase in NTx in the $-\mathrm{T},+\mathrm{E}$ group (Fig. 2A), which represented $\sim 30 \%$ of the NTx increase observed after complete sex steroid deficiency. In light of the mouse findings, this increase, which was not suppressible by estrogen, likely represents the loss of the direct effects of testosterone (without aromatization to estrogen) on bone resorption in cancellous bone. In this interpretation, the bulk of the effects of estrogen in human males may well be in cortical bone, which is fundamentally different in humans versus mice. Specifically, humans have extensive intracortical, osteonal remodeling that is absent in mice (Jikla 2013). Thus, consistent with the findings in the AR deletion mouse models, testosterone (in the absence of aromatization to estrogen) likely does regulate cancellous bone resorption in humans, but the regulation of cortical bone remodeling by estrogen is much more evident in human versus mouse males because of the fundamental differences in cortical bone between the species. Moreover, because $\sim 80 \%$ of the skeleton is cortical bone (Bonnick 1998), estrogen inevitably emerges as the more dominant regulator of bone metabolism in human males. 
Based on these considerations, Figure 5 attempts to synthesize the findings from the human and mouse models and presents a working hypothesis for the compartment-specific effects or estrogens versus androgens on bone in females and males. As described earlier, the major effect of castration in either sex is an increase in bone remodeling, with bone resorption outstripping bone formation, leading to bone loss. Thus, sex steroids collectively restrain the activation of bone remodeling, likely through effects on osteocytes, although this needs additional experimental validation using inducible deletion of sex steroid receptors in adult mice. As noted earlier, the distribution of ER $\alpha$ versus ER $\beta$ appears to be quite different in cancellous and cortical bone, with both receptors expressed in cancellous bone and $\mathrm{ER} \alpha$ predominating in cortical bone. Because ER $\beta$ antagonizes ER $\alpha$ in bone (Nicks et al. 2016) and other tissues (Hall and McDonnell 1999), a plausible hypothesis that is supported by human (Khosla et al. 2011) and mouse (Syed et al. 2010) data is that it would take higher levels of estrogen to suppress bone remodeling in cancellous as compared with cortical bone. In females (Fig. 5A), estrogen levels are sufficiently high so that estrogen consistently suppresses bone remodeling in both cortical and cancellous bone, with testosterone playing a minimal role in cancellous bone and no discernable role in cortical bone. Males, however, have much lower estrogen levels, which are able to suppress cortical bone remodeling and perhaps have some effects in cancellous bone, but males require substantial androgen action in cancel- lous bone to adequately restrain bone remodeling and prevent bone loss in that compartment as adults (Fig. 5B). Although lacking experimental proof in all aspects, this formulation is nonetheless consistent with the available data discussed in this perspective and does reconcile the seemingly disparate findings from humans versus mice, keeping in mind the fundamental difference in intracortical remodeling between species.

\section{SUMMARY AND CONCLUSIONS}

Since the original description by Fuller Albright of the effects of estrogen deficiency on bone in women (Albright 1940), there has been enormous progress in our understanding of sex steroid regulation of the skeleton. Studies in humans and mice have generally been concordant and helped define the target cells, the roles of $\mathrm{ER} \alpha, \mathrm{ER} \beta$, and $\mathrm{AR}$, and potential mediators of estrogen action on bone, albeit with less information on downstream targets of androgen action. The importance of estrogen action on bone is reflected by the fact that it is a key regulator of bone metabolism not only in women but also in men. Moreover, two of the new drugs developed in recent years for the treatment of osteoporosis, denosumab and romozosumab, target RANKL and sclerostin, respectivelymolecules that in humans and in mice have been implicated in mediating, at least in part, estrogen action on bone. Thus, continuing to better define the mechanisms of sex steroid action on bone will not only provide fundamental knowledge regarding the regulation of bone

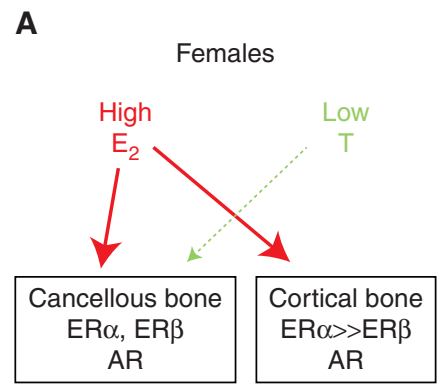

B

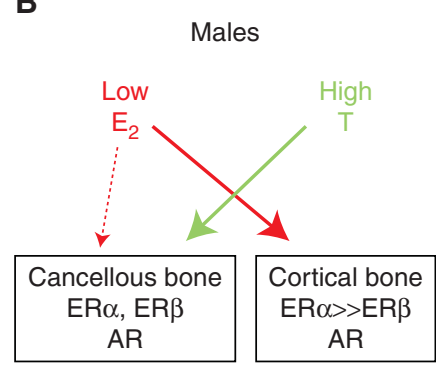

Figure 5. Working model to explain the differential effects of estrogen versus testosterone on cancellous and cortical bone. Please see text for further details. ER, Estrogen receptor; AR, androgen receptor. 
metabolism, but likely also identify additional therapeutic targets to treat osteoporosis.

\section{ACKNOWLEDGMENTS}

This work is supported by National Institutes of Health (NIH) Grants P01 AG004875, AG048792, AR027065, and AR068275.

\section{REFERENCES}

Albright F. 1940. Post-menopausal osteoporosis. Trans Assoc Am Physicians 55: 298-305.

Almeida M, Iyer S, Martin-Millan M, Bartell SM, Han L, Ambrogini E, Onal M, Xiong J, Weinstein RS, Jilka RL, et al. 2013. Estrogen receptor- $\alpha$ signaling in osteoblast progenitors stimulates cortical bone accrual. J Clin Invest 123: 394-404.

Almeida M, Laurent MR, Dubois V, Claessens F, O’Brien CA, Bouillon R, Vanderschueren D, Manolagas SC. 2017. Estrogens and androgens in skeletal physiology and pathophysiology. Physiol Rev 97: 135-187.

Bilezikian JP, Morishima A, Bell J, Grumbach MM. 1998. Increased bone mass as a result of estrogen therapy in a man with aromatase deficiency. $N$ Engl J Med 339: 599_ 603.

Bonnick SL. 1998. Skeletal anatomy in densitometry. In Bone densitometry in clinical practice (ed. Bonnick SL), pp. 35-78. Humana, New York.

Bord S, Horner A, Beavan S, Compston J. 2001. Estrogen receptors $\alpha$ and $\beta$ are differentially expressed in developing human bone. JClin Endocrinol Metab 86: 2309-2314.

Carani C, Qin K, Simoni M, Faustini-Fustini M, Serpente S, Boyd J, Korach KS, Simpson ER. 1997. Effect of testosterone and estradiol in a man with aromatase deficiency. N Engl J Med 337: 91-95.

Cauley JA, Robbins J, Chen Z, Cummings SR, Jackson RD, LaCroix AZ, LeBoff M, Lewis CE, McGowan J, Neuner J, et al. 2003. Effects of estrogen plus progestin on risk of fracture and bone mineral density. JAMA 290: 1729_ 1738.

Cauley JA, Wampler NS, Barnhart JM, Wu L, Allison M, Chen Z, Hendrix S, Robbins J, Jackson RD; Women's Health Initiative Observational Study. 2008. Incidence of fractures compared to cardiovascular disease and breast cancer: The Women's Health Initiative Observational Study. Osteoporos Int 19: 1717-1723.

Charatcharoenwitthaya N, Khosla S, Atkinson EJ, McCready LK, Riggs BL. 2007. Effect of blockade of TNF- $\alpha$ and interleukin-1 action on bone resorption in early postmenopausal women. J Bone Miner Res 22: 724-729.

Chiang C, Chiu M, Moore AJ, Anderson PH, GhasemZadeh A, McManus JF, Ma C, Seeman E, Clemens TL, Morris HA, et al. 2009. Mineralization and bone resorption are regulated by the androgen receptor in male mice. $J$ Bone Miner Res 24: 621-631.

Chung YE, Lee SH, Lee SY, Kim SY, Kim HH, Mirza FS, Lee SK, Lorenzo JA, Kim GS, Koh JM. 2012. Long-term treat- ment with raloxifene, but not bisphosphonates reduces circulating sclerostin levels in postmenopausal women. Osteoporos Int 23: 1235-1243.

Ciana P, Raviscioni M, Mussi P, Vegeto E, Que I, Parker MG, Lowik C, Maggi A. 2003. In vivo imaging of transcriptionally active estrogen receptors. Nat Med 9: 82-86.

Cosman F, Crittenden DB, Adachi JD, Binkley N, Czerwinski E, Ferrari S, Hofbauer LC, Lau E, Lewiecki EM Miyauchi A, et al. 2016. Romosozumab treatment in postmenopausal women with osteoporosis. $N$ Engl J Med 375: 1532-1543.

Cummings SR, San Martin J, McClung MR, Siris ES, Eastell R, Reid IR, Delmas P, Zoog HB, Austin M, Wang A, et al. 2009. Denosumab for prevention of fractures in postmenopausal women with osteoporosis. $N$ Engl J Med 361: 756-765.

Drake MT, Khosla S. 2017. Hormomal and systemic regulation of sclerostin. Bone 96: 8-17.

Eghbali-Fatourechi G, Khosla S, Sanyal A, Boyle WJ, Lacey DL, Riggs BL. 2003. Role of RANK ligand in mediating increased bone resorption in early postmenopausal women. J Clin Invest 111: 1221-1230.

Falahati-Nini A, Riggs BL, Atkinson EJ, O'Fallon WM, Eastell R, Khosla S. 2000. Relative contributions of testosterone and estrogen in regulating bone resorption and formation in normal elderly men. J Clin Invest 106: 1553-1560.

Farman HH, Windahl SH, Westberg L, Isaksson H, Egecioglu E, Schele E, Ryberg H, Jansson JO, Tuukkanen J, Koskela A, et al. 2016. Female mice lacking estrogen receptor $\alpha$ in hypothalamic pro-opimelanocortin (POMC) meurons display enhanced estrogenic response on cortical bone mass. Endocrinology 157: 3242-3252.

Farr JN, Roforth MM, Fujita K, Nicks KM, Cunningham JM, Atkinson EJ, Therneau TM, McCready LK, Peterson JM, Drake MT, et al. 2015. Effects of age and estrogen on skeletal gene expression in humans as assessed by RNA sequencing. PLoS ONE 10: e0138347.

Finkelstein JS, Lee H, Leder BZ, Burnett-Bowie S-AM, Goldstein DW, Hahn CW, Hirsch SC, Linker A, Perros N, Servais AB, et al. 2016. Gonadal steroid-dependent effects on bone turnover and bone mineral density in men. J Clin Invest 126: 1114-1125.

Fujita K, Roforth MM, Demaray S, McGregor UI, Kirmani S, McCready LK, Peterson JM, Drake MT, Monroe DG Khosla S. 2014. Effects of estrogen on bone mRNA levels of sclerostin and other genes relevant to bone metabolism in postmenopausal women. J Clin Endocrinol Metab 99: E81-E88.

Hall JM, McDonnell DP. 1999. The estrogen receptor $\beta$-isoform (ER- $\beta$ ) of the human estrogen receptor modulates ER- $\alpha$ transcriptional activity and is a key regulator of the cellular response to estrogens and antiestrogens. Endocrinology 140: 5566-5578.

Handelsman DJ, Sikaris K, Ly LP. 2016. Estimating age-specific trends in circulating testosterone and sex hormonebinding globulin in males and females across the lifespan. Ann Clin Biochem 53: 377-384.

Ivaska KK, Hentunen TA, Vaaraniemi J, Ylipahkala H, Pettersson K, Vaananen HK. 2004. Release of intact and fragmented osteocalcin molecules from bone matrix 
during bone resorption in vitro. J Biol Chem 279: 18361 18369.

Jikla RL. 2013. The relevance of mouse models for investigating age-related bone loss in humans. J Gerontol A Biol Sci Med Sci 68: 1209-1217.

Kawano H, Sato T, Yamada T, Matsumoto T, Sekine K, Watanabe T, Nakamura T, Fukuda T, Yoshimura K, Yoshizawa T, et al. 2003. Suppressive function of androgen receptor in bone resorption. Proc Natl Acad Sci 100: 9416-9421.

Kearns AE, Khosla S, Kostenuik PJ. 2008. Receptor activator of nuclear factor $\kappa \mathrm{B}$ ligand and osteoprotegerin regulation of bone remodeling in health and disease. Endocr Rev 29: $155-192$.

Khosla S. 2012. Odanacatib: Location and timing are everything. J Bone Miner Res 27: 506-508.

Khosla S. 2015. New insights into androgen and estrogen receptor regulation of the male skeleton. J Bone Miner Res 30: 1134-1137.

Khosla S, Melton LJ III, Atkinson EJ, O'Fallon WM, Klee GG, Riggs BL. 1998. Relationship of serum sex steroid levels and bone turnover markers with bone mineral density in men and women: A key role for bioavailable estrogen. J Clin Endocrinol Metab 83: 2266-2274.

Khosla S, Amin S, Orwoll E. 2008. Osteoporosis in men. Endocr Rev 29: 441-464.

Khosla S, Melton LJ III, Riggs BL. 2011. The unitary model for estrogen deficiency and the pathogenesis of osteoporosis: Is a revision needed? J Bone Miner Res 26: 441-451.

Kondoh S, Inoue K, Igarashi K, Sugizaki H, Shirode-Fukuda Y, Inoue E, Yu T, Takeuchi JK, Kanno J, Bonewald L, et al. 2014. Estrogen receptor $\alpha$ in osteocytes regulates trabecular bone formation in female mice. Bone 60: 68-77.

Lee SK, Kadono Y, Okada F, Jacquin C, Koczon-Jareml B, Adams DJ, Aguila HL, Choi Y, Lorenzo JA. 2006. T lymphocyte-deficient mice lose trabecular bone mass with ovariectomy. J Bone Miner Res 21: 1704-1712.

Li JY, Chassaing B, Tyagi AM, Vaccaro C, Luo T, Adams J, Darby TM, Weitzmann MN, Mulle JG, Gewirtz AT, et al. 2016. Sex steroid deficiency-associated bone loss is microbiota dependent and prevented by probiotics. J Clin Invest 126: 2049-2063.

Maatta JA, Buki KG, Gu G, Alanne MH, Vaaraniemi J, Liljenback H, Poutanen M, Harkonen P, Vaananen K. 2013. Inactivation of estrogen receptor $\alpha$ in bone-forming cells induces bone loss in female mice. FASEB J 27: 478-488.

Martin-Millan M, Almeida M, Ambrogini E, Han L, Zhao H, Weinstein RS, Jilka RL, O'Brien CA, Manolagas SC. 2010. The estrogen receptor- $\alpha$ in osteoclasts mediates the protective effects of estrogens on cancellous but not cortical bone. Mol Endocrinol 24: 323-334.

Masuzawa T, Miyaura C, Onoe Y, Kusano K, Ohta H, Nozawa S, Suda T. 1994. Estrogen deficiency stimulates B lymphopoiesis in mouse bone marrow. J Clin Invest 94: 1090-1097.

Melville KM, Kelly NH, Khan SA, Schimenti JC, Ross FP, Main RP, van der Meulen MCH. 2014. Female mice lacking estrogen receptor- $\alpha$ in osteoblast have compromised bone mass and strength. J Bone Miner Res 29: 370-379.

Modder UIL, Sanyal A, Kearns AE, Sibonga JD, Nishihara E, Xu J, O’Malley BW, Ritman EL, Riggs BL, Spelsberg TC, et al. 2004. Effects of loss of steroid receptor coactivator- 1 on the skeletal response to estrogen in mice. Endocrinology 145: 913-921.

Modder UI, Roforth MM, Hoey K, McCready LK, Peterson JM, Monroe DG, Oursler MJ, Khosla S. 2011a. Effects of estrogen on osteoprogenitor cells and cytokines/bone regulatory factors in postmenopausal women. Bone 49: 202-207.

Modder UIL, Clowes JA, Hoey K, Peterson JM, McCready L, Oursler MJ, Riggs BL, Khosla S. 2011b. Regulation of circulating sclerostin levels by sex steroids in women and men. J Bone Miner Res 26: 27-34.

Nakamura T, Imai Y, Matsumoto T, Sato S, Takeuchi K, Igarashi K, Harada Y, Azuma Y, Krust A, Yamamoto Y et al. 2007. Estrogen prevents bone loss via estrogen receptor $\alpha$ and induction of fas ligand in osteoclasts. Cell 130: 811-823.

Nakashima T, Hayashi M, Fukunaga T, Kurata K, Oh-hora M, Feng JQ, Bonewald LF, Kodama T, Wutz A, Wagner EF, et al. 2011. Evidence for osteocyte regulation of bone homeostasis through RANKL expression. Nat Med 17: 1231-1234.

Nicks KM, Fujita K, Fraser D, McGregor U, Drake MT, McGee-Lawrence ME, Westendorf JJ, Monroe DG, Khosla S. 2016. Deletion of estrogen receptor $\beta$ in osteoprogenitor cells increases trabecular but not cortical bone mass in female mice. J Bone Miner Res 31: 606-614.

Niziolek PJ, Bullock W, Warman ML, Robling AG. 2015. Missense mutations in LRP5 associated with high bone mass protect the mouse skeleton from discuse and ovariectomy-induced osteopenis. PLos ONE 10: e0140775.

Notini AJ, McManus JF, Moore A, Bouxsein M, Jimenez M, Chiu WSM, Glatt V, Kream BE, Handelsman DJ, Morris HA, et al. 2007. Osteoblast deletion of exon 3 of the androgen receptor gene results in trabecular bone loss in adult male mice. J Bone Miner Res 22: 347-356.

Ohlsson C, Engdahl C, Borjesson AE, Windahl SH, Studer E, Westberg L, Eriksson E, Koskela A, Tuukkanen J, Krust A, et al. 2012. Estrogen receptor- $\alpha$ expression in neuronal cells affects bone mass. Proc Natl Acad Sci 109: 983-988.

Onal M, Xiong J, Chen X, Thostenson JD, Almeida M, Manolagas SC, O’ Brien CA. 2012. Receptor activator of nuclear factor $\kappa \mathrm{B}$ ligand (RANKL) protein expression by B lymphocytes contributes to ovariectomy-induced bone loss. J Biol Chem 287: 29851-29860.

Oursler MJ, Osdoby P, Pyfferoen J, Riggs BL, Spelsberg TC. 1991. Avian osteoclasts as estrogen target cells. Proc Natl Acad Sci 88: 6613-6617.

Oursler MJ, Pederson L, Fitzpatrick L, Riggs BL. 1994. Human giant cell tumors of the bone (osteoclastomas) are estrogen target cells. Proc Natl Acad Sci 91: 5227-5231.

Pacifici R. 2012. Role of T cells in ovariectomy induced bone loss-Revisited. J Bone Miner Res 27: 231-239.

Prior JC. 1990. Progesterone as a bone-trophic hormone. Endocr Rev 11: 386-398.

Raisz LG, Wiita B, Artis A, Bowen A, Schwartz S, Trahiotis M, Shoukri K, Smith J. 1996. Comparison of the effects of estrogen alone and estrogen plus androgen on biochemical markers of bone formation and resorption in postmenopausal women. J Clin Endocrinol Metab 81: 37-43. 
Riggs BL, Khosla S, Melton LJ III. 2002. Sex steroids and the construction and conservation of the adult skeleton. Endocr Rev 23: 279-302.

Simpson ER, Zhao Y, Agarwal VR, Michael MD, Bulun SE, Hinshelwood MM, Graham-Lorence S, Sun T, Fisher CR, Qin K, et al. 1997. Aromatase expression in health and disease. Recent Prog Horm Res 52: 185-214.

Sims NA, Dupont S, Krust A, Clement-Lacroix P, Minet D, Resche-Rigon M, Gaillard-Kelly M, Baron R. 2002. Deletion of estrogen receptors reveals a regulatory role for estrogen receptors $\beta$ in bone remodeling in females but not in males. Bone 30: 18-25.

Sinnesael M, Claessens F, Laurent M, Dubois V, Boonen S, Deboel L, Vanderschueren D. 2012. Androgen receptor (AR) in osteocytes is important for the maintenance of male skeletal integrity: Evidence from targeted AR disruption in mouse osteocytes. J Bone Miner Res 27: 2535-2543.

Smith EP, Boyd J, Frank GR, Takahashi H, Cohen RM, Specker B, Williams TC, Lubahn DB, Korach KS. 1994. Estrogen resistance caused by a mutation in the estrogenreceptor gene in a man. $N$ Engl J Med 331: 1056-1061.

Smith EP, Specker B, Bachrach BE, Kimbro KS, LI XJ, Young MF, Fedarko NS, Abuzzahab MJ, Frank GR, Cohen RM, et al. 2008. Impact on bone of an estrogen receptor- $\alpha$ gene loss of function mutation. J Clin Endocrinol Metab 93: 3088-3096.

Sowers MR, Zheng H, Greendale GA, Neer RM, Cauley JA, Ellis J, Johnson S, Finkelstein JS. 2013. Changes in bone resorption across the menopause transition: Effects of reproductive hormones, body size, and ethnicity. J Clin Endocrinol Metab 98: 2854-2863.

Stepan JJ, Lachman M, Zverina J, Pacovsky V. 1989. Castrated men exhibit bone loss: Effect of calcitonin treatment on biochemical indices of bone remodeling. J Clin Endocrinol Metab 69: 523-527.

Syed FA, Modder UI, Roforth M, Hensen I, Fraser DG, Peterson JM, Oursler MJ, Khosla S. 2010. Effects of chronic estrogen treatment on modulating age-related bone loss in female mice. J Bone Miner Res 25: 2438 2446.

Tu X, Delgado-Calle J, Condon KW, Maycas M, Zhang H, Carlesso N, Taketo MM, Burr DB, Plotkin LI, Bellido T. 2015. Osteocytes mediate the anabolic actions of canonical Wnt/ $\beta$-catenin signaling in bone. Proc Natl Acad Sci 112: E478-E486.

Ucer S, Iyer S, Bartell SM, Martin-Millan M, Han L, Kim HN, Weinstein LS, Jilka RL, O’Brien CA, Almeida M, et al. 2015. The effects of androgens on murine cortical bone do not require $\mathrm{AR}$ or $\mathrm{ER} \alpha$ signaling in osteoblasts and osteoclasts. J Bone Miner Res 30: 1138-1149.

Ucer S, Iyer S, Kim HN, Han L, Rutlen C, Allison K, Thostenson JD, de Cabo R, Jilka RL, O’Brien CA, et al. 2016. The effects of aging and sex steroid deficiency on the murine skeleton are independent and mechanistically distinct. J Bone Miner Res 32: 560-574.

Weitzmann MN, Pacifici R. 2006. Estrogen deficiency and bone loss: An inflammatory tale. J Clin Invest 116: 11861194.

Windahl SH, Vidal O, Andersson G, Gustafsson JA, Ohlsson C. 1999. Increased cortical bone mineral content but unchanged trabecular bone mineral density in female $E R \beta^{-/-}$mice. J Clin Invest 104: 895-901.

Windahl SH, Borjesson AE, Farman HH, Engdahl C, Moverare-Skrtic S, Sjogren K, Lagerquist MK, Kindblom JM, Koskela A, Tuukkanen J, et al. 2013. Estrogen receptor- $\alpha$ in osteocytes is important for trabecular bone formation in male mice. Proc Natl Acad Sci 110: $2294-$ 2299.

Yeh S, Tsai MY, Xu Q, Mu XM, Lardy H, Huang KE, Lin H, Yeh SD, Altuwaijri S, Zhou X, et al. 2002. Generation and characterization of androgen receptor knockout (ARKO) mice: An in vivo model for the study of androgen functions in selective tissues. Proc Natl Acad Sci 99: 13498 13503. 


\section{$\&_{\mathrm{CSH}}^{\infty} \&$ Cold Spring Harbor

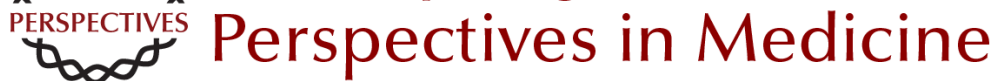

\section{Regulation of Bone Metabolism by Sex Steroids}

Sundeep Khosla and David G. Monroe

Cold Spring Harb Perspect Med 2018; doi: 10.1101/cshperspect.a031211 originally published online July 14,2017

Subject Collection Bone: A Regulator of Physiology

\section{Mechanism of Bone Mineralization} Monzur Murshed

Neural Regulation of Bone and Bone Marrow Maria Maryanovich, Shoichiro Takeishi and Paul S. Frenette

Regulation of Bone Remodeling by Parathyroid Hormone Marc N. Wein and Henry M. Kronenberg

The Bone Marrow Microenvironment in Health and Myeloid Malignancy

Marta Galán-Díez, Álvaro Cuesta-Domínguez and Stavroula Kousteni

The Biology of Bone Metastasis

Mark Esposito, Theresa Guise and Yibin Kang

Bone Remodeling and the Microbiome Roberto Pacifici

\section{Osteoimmunology}

Kazuo Okamoto and Hiroshi Takayanagi

Multiple Myeloma and Bone: The Fatal Interaction Silvia Marino and G. David Roodman

Biology of Bone: The Vasculature of the Skeletal System

Emma C. Watson and Ralf H. Adams

Regulation of Energy Metabolism by

Bone-Derived Hormones

Paula Mera, Mathieu Ferron and Ioanna Mosialou

\section{Biology of Fibroblast Growth Factor 23: From \\ Physiology to Pathology \\ Marie Courbebaisse and Beate Lanske}

Regulation of Bone Metabolism by Sex Steroids Sundeep Khosla and David G. Monroe

For additional articles in this collection, see http://perspectivesinmedicine.cshlp.org/cgi/collection/ 